\title{
Electrodeposition of Tin from Tartrate Solutions
}

\author{
J. Torrent-Burgués, ${ }^{*}$ E. Guaus \\ Dep. Enginyeria Química, Univ. Politècnica de Catalunya, C/ Colom 1, 08222-Terrassa, \\ Barcelona, Spain.
}

Received 7 February 2005; accepted in revised form 26 September 2005

\begin{abstract}
The electrodeposition of tin in presence of tartrate ions has been analysed by electrochemical techniques, mainly chronoamperometry, and by scanning electron microscopy (SEM). The obtained values of nucleus density with both techniques have been compared and discussed. The electrodeposition process follows an instantaneous nucleation with 3D growth under diffusion control at the initial times of the process, but a second nucleation process occurs at higher times. The influence of tartrate and of agitation conditions is also inferred from the crystal morphology.
\end{abstract}

Keywords: tartrate solution, tin electrodeposition, SEM, nucleus density.

\section{Introduction}

Tin has been generally applied as a coating to impart corrosion resistance, enhance appearance or improve solder ability. There is increasing interest in tin used as a substitute for conventional coatings [1-4] because it has much less environmental impact. Recently published studies on tin and tin-alloy electrodeposition, focus on the influence of either additives, bath compositions or plating variables [5-14]. In a previous paper [13], the general voltammetric and chronoamperometric characteristics of tin electrodeposition from sulphatetartrate baths was reported. In this study, the electrodeposition of tin from a bath with slightly different composition is reported using potentiodynamic and potentiostatic electrochemical techniques and scanning electron microscopy, in order to analyse the deposit morphology and the deposition mechanism.

\footnotetext{
* Corresponding author. E-mail address: juan.torrent@upc.edu
} 


\section{Experimental}

The electrochemical measurements were performed in a three electrode cell using a vitreous carbon electrode as working electrode (area $=0.031 \mathrm{~cm}^{2}$ ), a platinum wire as counter electrode and $\mathrm{Ag} / \mathrm{AgCl} / \mathrm{KCl}(3 \mathrm{M})$ as reference electrode, inserted in a Luggin capillary. All potentials reported in the text are referred to this electrode. An AUTOLAB PSTAT20 was used as potentiostat controlled by a microcomputer. Voltammetric experiments were carried out at $50 \mathrm{mV} \mathrm{s}$, scanning at first to negative potentials. Only one cycle was run in each experiment. Chronoamperometric experiments were carried out by stepping from an initial potential of $-200 \mathrm{mV}$ to the selected final potential.

After the electrochemical deposition of tin, the electrode was removed from the plating solution and rinsed with Millipore pure water. The deposit morphology was examined using a Jeol Cambridge L-120 scanning electron microscope. The presented SEM images were obtained at amplifications of 2000 and 6000, and a metric bar is also present in each figure.

Chemicals used were $\mathrm{SnSO}_{4}$, tartaric acid $\left(\mathrm{C}_{4} \mathrm{H}_{6} \mathrm{O}_{6}\right)$, sulphuric acid, sodium hydroxide and $\mathrm{Na}_{2} \mathrm{SO}_{4}$ analytical grade. All solutions were freshly prepared with water, first distilled and then treated with a Millipore Milli Q system. The bath at $\mathrm{pH}=4$ contained $\mathrm{Na}_{2} \mathrm{SO}_{4} 1 \mathrm{M}$ as supporting electrolyte and tartaric acid $0.12 \mathrm{M}$ as chelating agent; the $\mathrm{pH}$ was adjusted using sodium hydroxide. In all cases the $\mathrm{SnSO}_{4}$ concentration was $0.02 \mathrm{M}$. Before each experiment the solution was deaerated with argon. The working electrode was polished mechanically before each run with alumina powder of 3.75 and $1.87 \mu \mathrm{m}$ and followed by a short electrochemical conditioning. The experiments were performed at $25^{\circ} \mathrm{C}$.

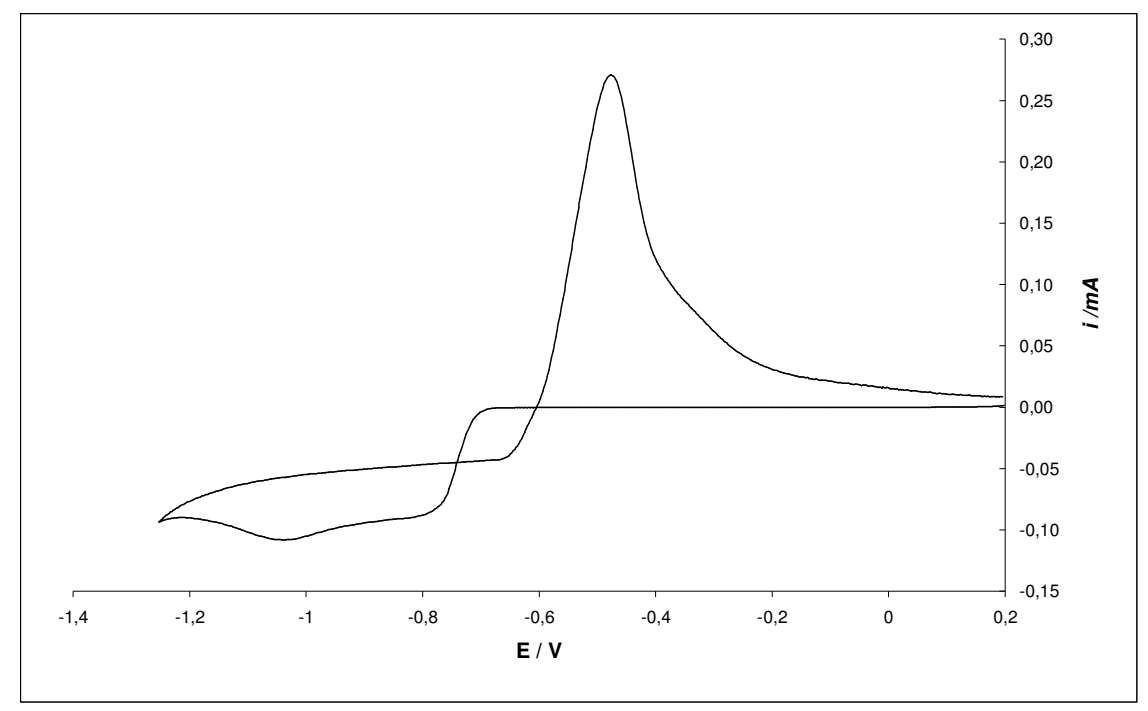

Figure 1. Voltammetric curve at $50 \mathrm{mV} \mathrm{s}^{-1}$ for the solution $0.02 \mathrm{M} \mathrm{SnSO}_{4}, 1 \mathrm{M}$ $\mathrm{Na}_{2} \mathrm{SO}_{4}, 0.12 \mathrm{M}$ tartaric acid and $\mathrm{pH}=4$. 


\section{Results and discussion}

\section{Voltammetric results}

Fig. 1 shows the voltammetric response of tin electrodeposition in a sulphatetartrate bath. The characteristics of the curve coincide with those previously reported in slightly different conditions [13]. The electrodeposicion process starts at around $-680 \mathrm{mV}$ and in the reduction scan two peaks are clearly observed, at around -810 and $-1035 \mathrm{mV}$. On the other hand, in the anodic scan a principal peak occurs at around $-475 \mathrm{mV}$, followed by a shoulder at more positive potentials.
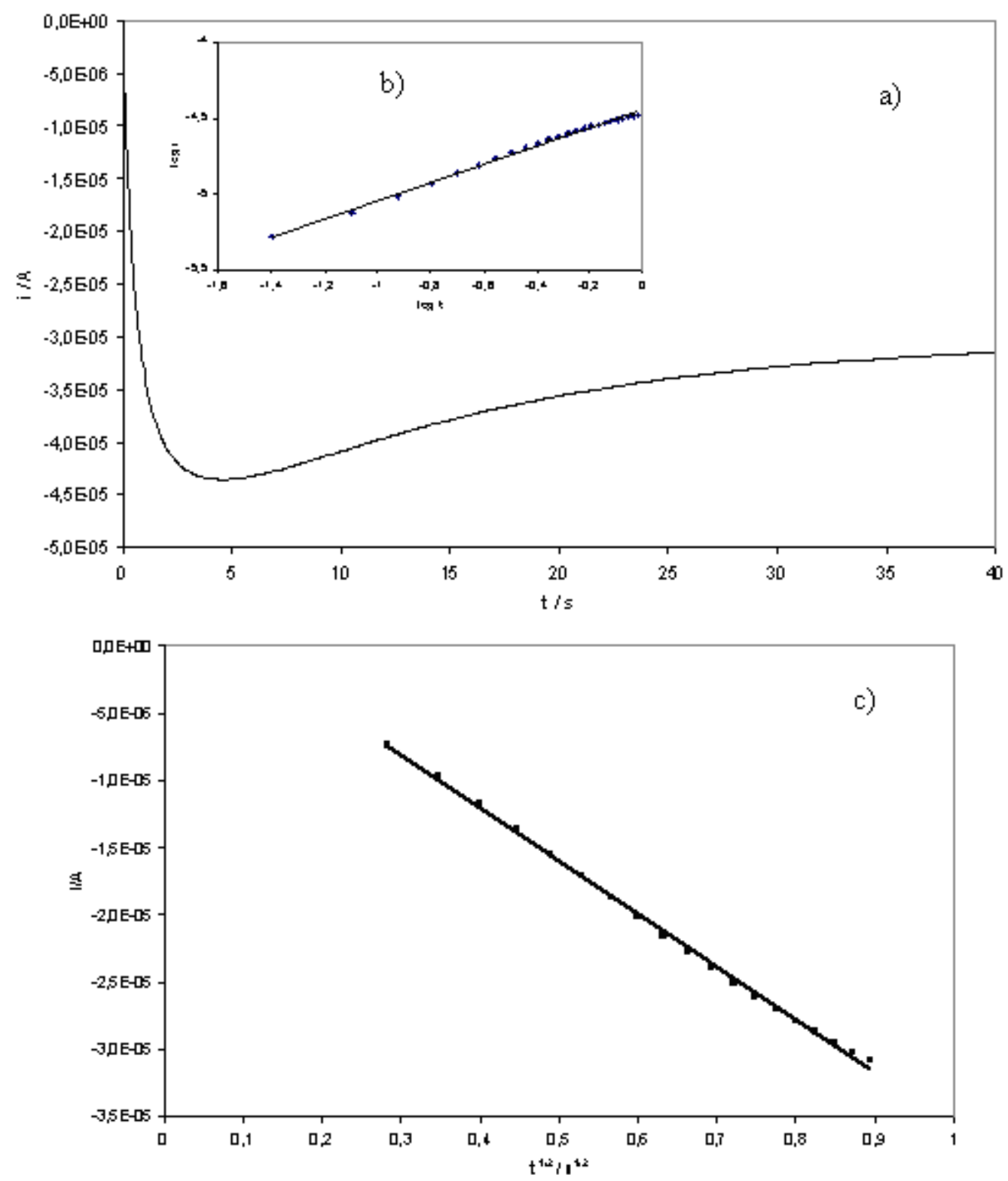

Figure 2. a) Chronoamperometric curve for solution $0.02 \mathrm{M} \mathrm{SnSO}_{4}, 1 \mathrm{M} \mathrm{Na}_{2} \mathrm{SO}_{4}, 0.12$ $\mathrm{M}$ tartaric acid and $\mathrm{pH}=4$. The potential step transient was made from $\mathrm{E}_{\mathrm{o}}=-300 \mathrm{mV}$ to $E_{d}=-750 \mathrm{mV}$. b) Inset: $\log i$ versus $\log t$ plot. c) plot of $i$ versus $t^{1 / 2}$. 


\section{Chronoamperometric curves and SEM micrographs}

Fig. 2a shows the intensity current-time, i-t, curve recorded for the corresponding electrodeposit without agitation at a potential of $-750 \mathrm{mV}$. In order to elucidate the possible mechanism of the electrodeposition process, several analyses have been done. The induction time has been considered in the analysis, but it is zero in the reported experimental conditions. At first, the plot of $\log \mathrm{i}$ versus $\log \mathrm{t}$ (Fig. 2b, inset of Fig. 2a), for the initial part of the chronoamperometric curve, is linear with slope close to 0.5 . This slope value corresponds to an instantaneous nucleation (IN) with 3D growth under diffusion control. This mechanism is also confirmed, at the initial part, with the non-dimensional plot [15] of $\left(\mathrm{i} / \mathrm{i}_{\mathrm{m}}\right)^{2}$ versus $\left(t / t_{m}\right)$, see Fig. 3, where $i_{m}$ and $t_{m}$ are the current and the time at the maximum in the chronoamperometric curve. This mechanism coincides with that reported in a previous work [13] with different experimental conditions. At longer times, especially $t>t_{m}$, the experimental curve separates from the theoretical curve for an IN 3D growth under diffusion control (Fig. 3), and also the i-t transient does not follow the $\mathrm{t}^{-1 / 2}$ dependence of the Cottrell equation for a diffusion regime. This behaviour has been observed in other deposition processes [16]. This fact indicates that a kinetic control must also be considered in this part [16].

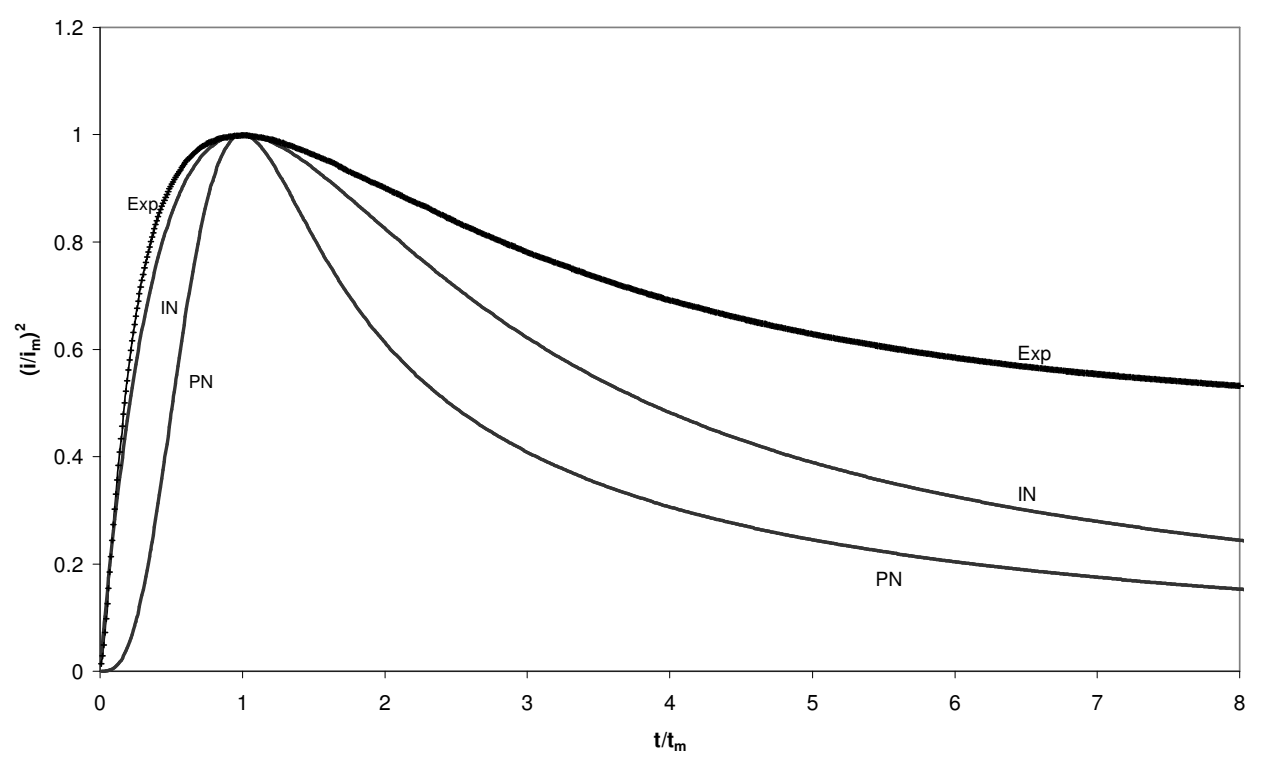

Figure 3. Non-dimensional plot $\left(\mathrm{i} / \mathrm{i}_{\mathrm{m}}\right)^{2}$ vs. $\left(\mathrm{t} / \mathrm{t}_{\mathrm{m}}\right)$ for the $\mathrm{i}$-t curve of Fig. 2.

From the slope in the plot of Fig. 2c and the equation 1 [13,15,17-19], it is possible to obtain the nucleus density $\mathrm{N}^{*}$,

$$
i=k t^{1 / 2} \quad \text { with } \quad k=\pi z F\left(\frac{M}{\rho}\right)^{1 / 2}(D c)^{3 / 2} N^{*} A
$$

where $\mathrm{M}$ is the atomic weight of tin, $\rho$ is the solid density, and $\mathrm{A}$ is the surface electrode area. In our case, $M=118.69 \mathrm{~g} \mathrm{~mol}^{-1}, \rho=7.3 \mathrm{~g} \mathrm{~cm}^{-3}, \mathrm{z}=2, F=96485$ $\mathrm{C} / \mathrm{mol} \mathrm{e} \mathrm{e}^{-}, \mathrm{c}=2 \times 10^{-5} \mathrm{~mol} \mathrm{~cm} \mathrm{~cm}^{-3}, \mathrm{D}=1 \times 10^{-5} \mathrm{~cm}^{2} \mathrm{~s}^{-1}$ [13], and $\mathrm{A}=0.031 \mathrm{~cm}^{2}$. 
Substituting these values and the determined value of $\mathrm{k}=3.8 \times 10^{-5} \mathrm{~A} \mathrm{~s}^{-1 / 2}$, in equation (1), it is obtained that $\mathrm{N}^{*}=1.8 \times 10^{5} \mathrm{~cm}^{-2}$. A similar value of $\mathrm{N}^{*}$ is obtained from the set of equations 2 of the non-dimensional analysis [15] for a IN 3D process under diffusion control, replacing the experimental values of $t_{m}$ and $\mathrm{i}_{\mathrm{m}}$.

$$
\begin{gathered}
t_{m}=\frac{1.2564}{N^{*} \pi k D} \quad i_{m}=0.6382 z F D c A\left(k N^{*}\right)^{1 / 2} \quad N^{*}=\frac{0.065}{k}\left(\frac{z F c A}{i_{m} t_{m}}\right)^{2} \\
k=\left(\frac{8 \pi c M}{\rho}\right)^{1 / 2}
\end{gathered}
$$

Fig. 4 shows the non-dimensional plot for other experimental conditions, which present a good agreement, also in the initial part, with a IN-3D process under diffusion control. For these experimental conditions, the values of $\mathrm{N}^{*}$ obtained from equations 2 also agree with those obtained using equation 1 . The values of $\mathrm{N}^{*}$ calculated with equation 1 for the experiments corresponding to curves $4 \mathrm{~b}$ and $4 \mathrm{c}$ were reported previously [13]. For the experiment corresponding to curve $4 \mathrm{a}$, the obtained value of $\mathrm{N}^{*}$ is $2.3 \times 10^{5} \mathrm{~cm}^{-2}$.

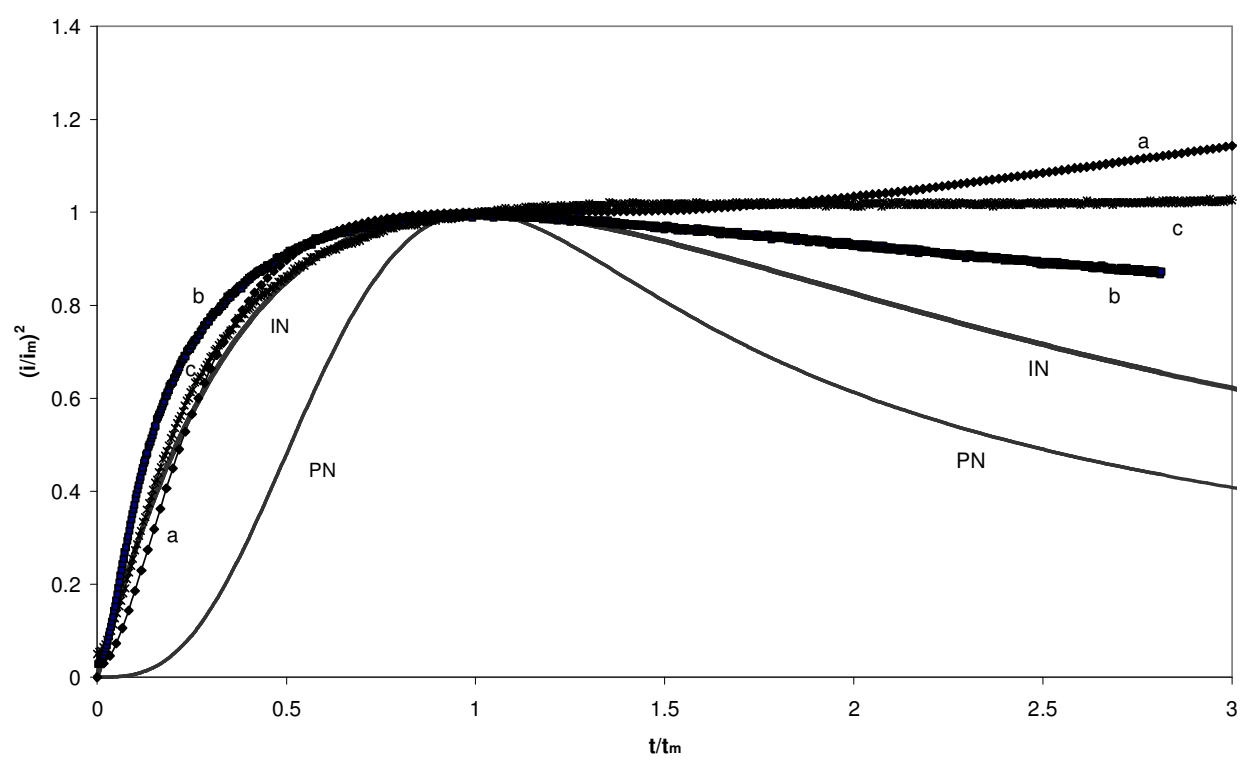

Figure 4. Non-dimensional plot for the i-t curves of the following experimental conditions: a) solution $0.02 \mathrm{M} \mathrm{SnSO}_{4}, 1 \mathrm{M} \mathrm{Na}_{2} \mathrm{SO}_{4}, 0.12 \mathrm{M}$ tartaric acid and $\mathrm{pH}=4$, $\mathrm{E}_{\mathrm{d}}=-800 \mathrm{mV}$; b and c) solution $0.01 \mathrm{M} \mathrm{SnSO}_{4}, 0.9 \mathrm{M} \mathrm{Na}_{2} \mathrm{SO}_{4}, 0.2 \mathrm{M}$ tartaric acid and $\mathrm{pH}=4, \mathrm{~b}) \mathrm{E}_{\mathrm{d}}=-800 \mathrm{mV}$, and c) $\mathrm{E}_{\mathrm{d}}=-850 \mathrm{mV}$.

Fig. 5 shows scanning electron microscopy (SEM) images of the obtained deposit without agitation at a potential of $-750 \mathrm{mV}$. The SEM image shows the presence of big crystals and also other smaller crystals. This fact seems to indicate that a second process of nucleation takes place in the electrodeposition, which could be responsible in part of the deviation observed at higher times in 
the analysis of the i-t curves respect to the IN 3D mechanism (see Fig. 3). The nucleus density obtained from the SEM micrograph, and considering only the bigger crystals, is approximately $2.8 \times 10^{7} \mathrm{~cm}^{-2}$. This value is still much higher than that obtained from equation 1. A similar discrepancy was observed by one of the authors in the electrodeposition of $\mathrm{Hg}$ on $\mathrm{Pt}$ [19] using both electrochemical and light scattering techniques, where the nucleus density values obtained by light scattering at higher overpotentials were higher than those obtained by chronoamperometry. A possible factor for this disagreement could be in the value of the diffusion coefficient D. Using the following equation (3) for the non-dimensional analysis of the chronoamperometric transients [15], it is obtained a lower value of $\mathrm{D}=3 \times 10^{-6} \mathrm{~cm}^{2} \mathrm{~s}^{-1}$.

$$
i_{m}^{2} t_{m}=0.1629(z F c)^{2} D
$$

This lower value will be in agreement with the fact that tin ions are complexed by tartrate anions. Introducing this new value of $D$ in equations 1 and 2 , the resulting value of $\mathrm{N}^{*}$ is $1.1 \times 10^{6} \mathrm{~cm}^{-2}$, a value closer to that obtained by SEM. The remaining disagreement can be attributed to the effects of heterodispersity and overlap and also to uncertainty in the calculation of $\mathrm{N}$ from the current transient at short times, because equation 1 for high values of $\mathrm{N}$ only applies at quite short times. Also, the presence of hydrogen evolution could difficult the correct application of the previous equations. This point has been discussed by Oskam et al. [16]. These authors have found that a significant discrepancy exists between $\mathrm{N}^{*}$ values determined from SEM and the current transient at potentials where hydrogen evolution proceeds, and that the electrochemically calculated nucleus density would be underestimated by a factor 16 in their system. In our system we have also observed an important hydrogen evolution [20], which can be responsible for the observed discrepancy. These discrepancies between $\mathrm{N}^{*}$ values obtained from different methods are not always remarked in the published papers. For instance, we have calculated the $\mathrm{N}^{*}$ values from SEM images in the paper of Márquez et al. [21] and also an important disagreement results between these values and those reported using the current transients, being the later between one and two orders of magnitude lower.

Deposits obtained without agitation (Fig. 5) present crystals of well defined morphology, some of them elongated with the characteristic tetragonal morphology of tin crystals [14]. Deposits made with agitation (Fig. 6), at the same deposition potential and deposition time, present bigger crystals, not so elongated as those without agitation (Fig. 5), and in most of the cases the big crystals show coalescence (Fig. 6B). The same effect due to agitation was observed in the presence of gluconate [14].

The occurrence of secondary nucleation processes is also evident in SEM images of deposits obtained at longer times, Fig. 7 and 8. This phenomenon is more important in no agitation conditions (Fig. 7) than in presence of agitation (Fig. 8). 


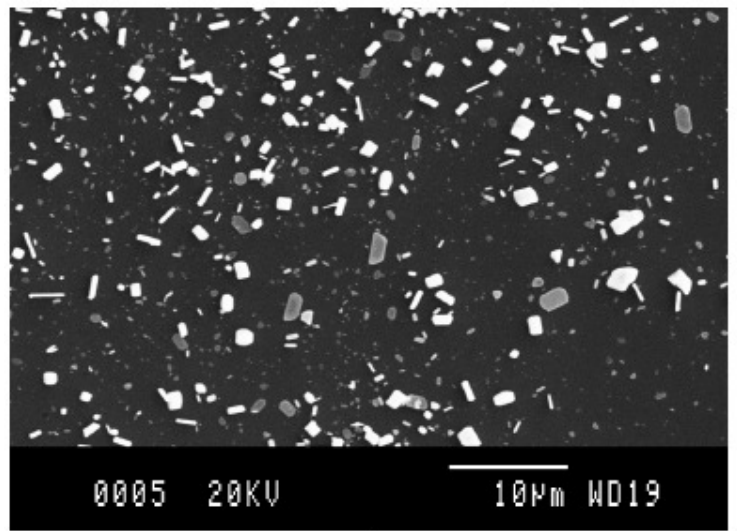

A

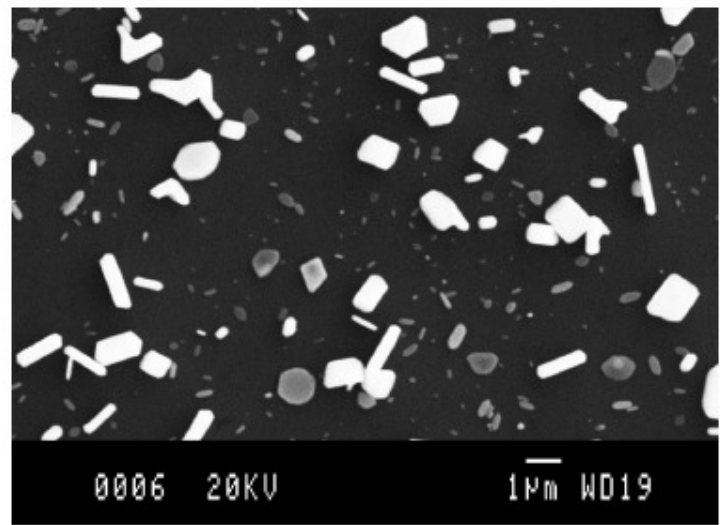

$\mathrm{B}$

Figure 5. SEM micrographs of deposits obtained at $-750 \mathrm{mV}$ and $40 \mathrm{~s}$ without agitation for the solution indicated in Fig. $2(\mathrm{Q}=1.4 \mathrm{mC})$. Image $\mathrm{B}$ is obtained doing a zoom in the zone of image A.

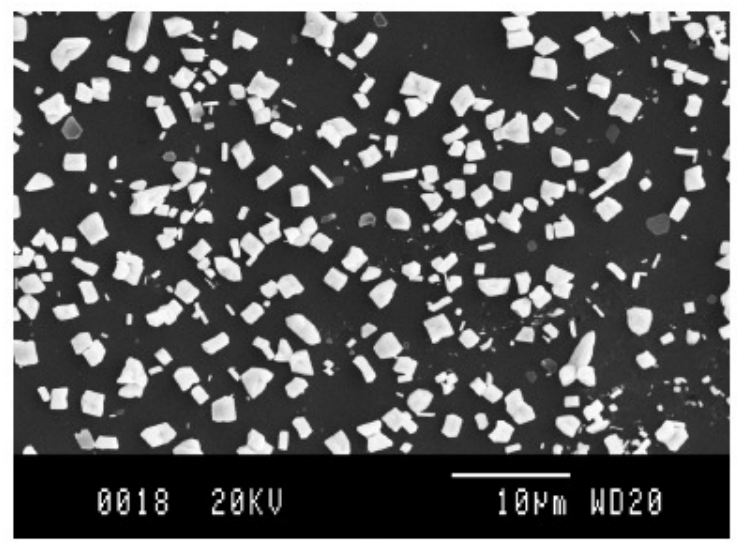

A

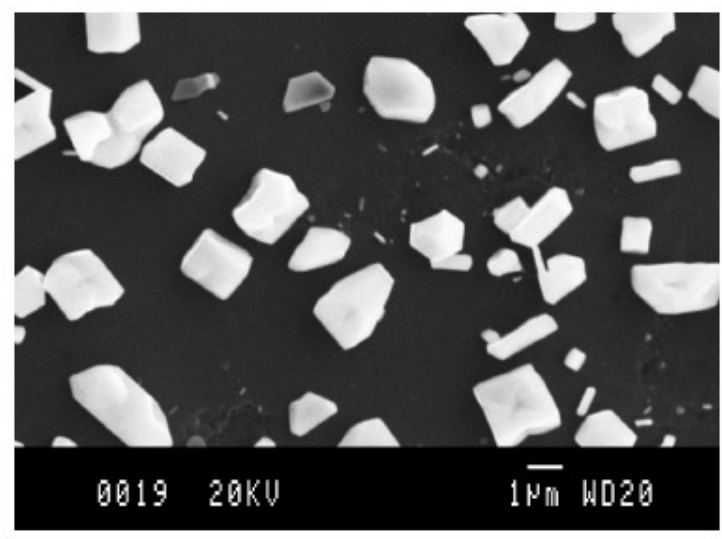

B

Figure 6. SEM micrographs of deposits obtained at $-750 \mathrm{mV}$ and $40 \mathrm{~s}$ with agitation for the solution indicated in Fig. $2(\mathrm{Q}=5.6 \mathrm{mC})$. Image $\mathrm{B}$ is obtained doing a zoom in the zone of image A.

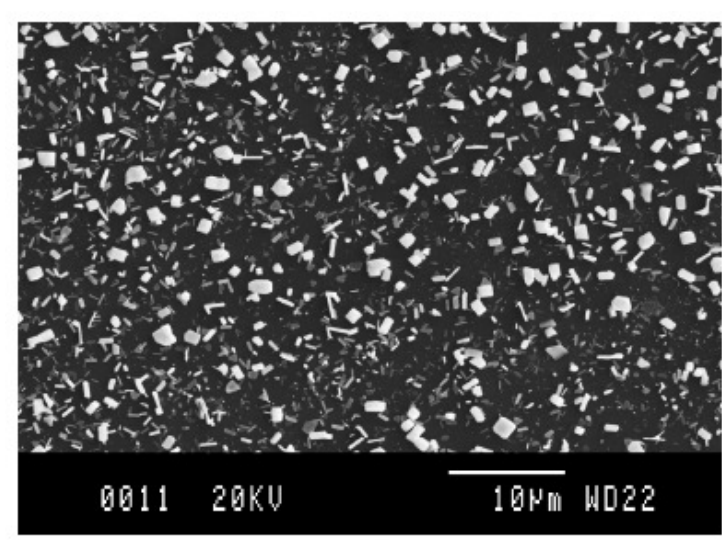

A

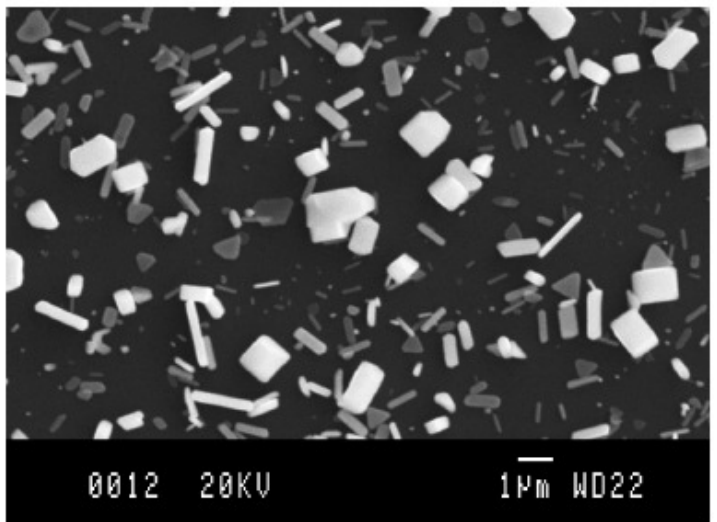

B

Figure 7. SEM micrographs of deposits obtained at $-750 \mathrm{mV}$ and $100 \mathrm{~s}$ without agitation for the solution indicated in Fig. $2(\mathrm{Q}=2.9 \mathrm{mC})$. Image $\mathrm{B}$ is obtained doing a zoom in the zone of image A. 


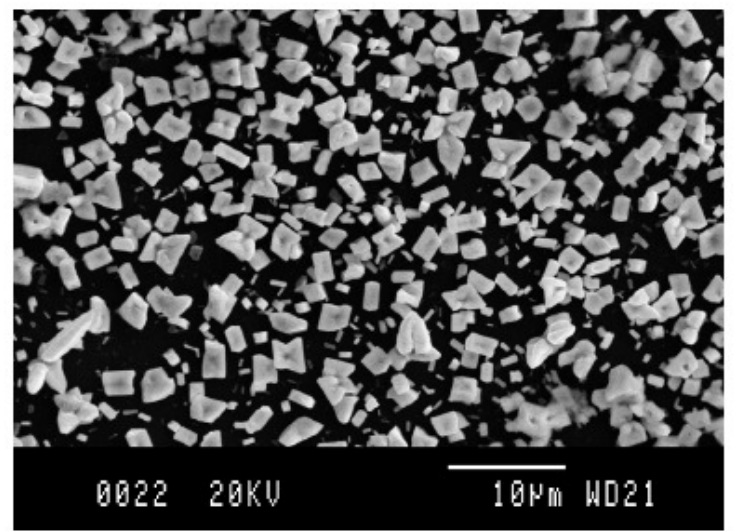

A

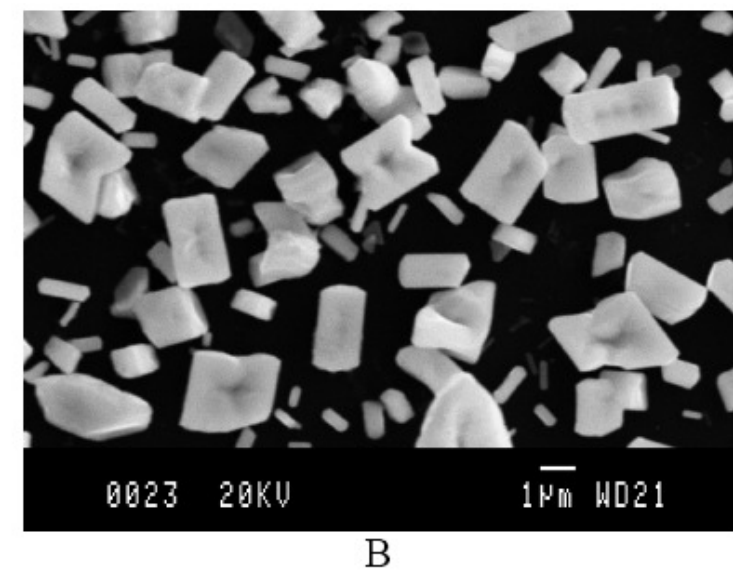

B

Figure 8. SEM micrographs of deposits obtained at $-750 \mathrm{mV}$ and $100 \mathrm{~s}$ with agitation for the solution indicated in Fig. $2(\mathrm{Q}=14.0 \mathrm{mC})$. Image $\mathrm{B}$ is obtained doing a zoom in the zone of image A.

\section{References}

1. R. Sabitha, M. Pushpavanam, M. Mahesh Sujatha, T. Vasudevan, Trans. Met. Finish. Ass. India 5 (1996) 267.

2. K.G. Sheppard. Abstracts of the $190^{\text {th }}$ Meeting of The Electrochemical Society, vol 96-2, $\mathrm{n}^{\mathrm{o}}$ 306, pg. 395, The Electrochemical Society, Pennington, NJ, (1996).

3. Y. Kim, B. Young Yang, Surf. Coating Technology 64 (1994) 99.

4. St. Vitkova, V. Ivanova, G. Raichevsky, Surf. Coating Technology 82 (1996) 226.

5. M.I. Smirnov, K.M. Tyutina and A.N. Popov, Russian J. Electrochem. 31 (1995) 498.

6. V.S. Vasantha, M. Pushpavanam and V.S. Muralidharan, Met. Finish. 93 (1995) 16.

7. O.A. Ashiru, J. Shirokoff, Appl. Surf. Science 103 (1996) 159.

8. G.S. Tzeng, S.H. Lin, Y.Y. Wang and C.C. Wan, J. Appl. Electrochem. 26 (1996) 419.

9. V.S. Vasantha, M. Pushpavanam, P. Kanaraj and V.S. Muralidharan, Trans. Inst. Met Finish. 74 (1996) 28.

10. S.S. Abd el Rehim, S.A. Refaey, G. Schwitzgebel, F. Taha and M.B. Saleh, J. Appl. Electrochem. 26 (1996) 413.

11. M. An, Y. Zhang, J. Zhang, Z. Tu, Plat. Surf. Finishing 85 (1999) 130.

12. I.A. Carlos, C.A.C. Souza, E.M.J.A. Pallone, R.H-P. Francisco, V. Cardoso, B.S. Lima-Neto, J. Appl. Electrochem. 30 (2000) 987.

13. E. Guaus, J. Torrent-Burgués, Portug. Electrochim. Acta 19 (2001) 247.

14. J. Torrent-Burgués, E. Guaus, F. Sanz, J. Appl. Electrochem. 32 (2002) 225.

15. B. Scharifker, G. Hills, Electrochim. Acta 28 (1983) 879.

16. G. Oskam, P.M. Vereecken, P.C. Searson, J. Electrochem. Soc. 146 (1999) 1436. 
17. P.J. Sonneveld, W. Visscher, E. Barendrecht, Electrochim. Acta 37 (1992) 1199.

18. P. Allongue, E. Souteyrand, J. Electroanal. Chem. 286 (1990) 217.

19. J. Torrent-Burgués, pg 1094 in Progress in the Understanding and Prevention of Corrosion, Ed. A.D. Mercer and J.M. Costa, IM-EFC, 1993.

20. E. Guaus, J. Torrent-Burgués, Russian J. Electrochem., to be published.

21. K. Márquez, G. Staikov, J.W. Schulze, Electrochim. Acta 48 (2003) 875. 
